\title{
La resignificación de la profesión docente a partir de los procesos integrados de formación permanente y la evaluación pedagógica
}

The new meaning of the teaching profession from the integrated processes of permanent training and the pedagogical evaluation

\section{Luz Stella Garcia Carrillo}

\section{Resumen}

\begin{abstract}
La profesión docente se enfrenta a situaciones que provocan su deterioro, los educadores colombianos afrontan la agresión, la falta de reconocimiento, de valoración, de estímulos. Este articulo presenta a la discusión la necesidad de resignificar la profesión docente a partir de procesos integrados de formación permanente y de evaluación de docentes desde la tendencia de desarrollo personal y profesional, que conlleven la transformación cualitativa para el mejoramiento de la escuela, y prácticas que a largo plazo propenden a lograr este objetivo. Estas circunstancias son igualmente válidas para los profesionales de la educación física.
\end{abstract}

Palabras clave: Resignificación de la profesión docente, profesores de educación física, evaluación de docentes, rendición de cuentas, desarrollo personal y profesional, formación permanente.

\section{Abstract}

The teaching profession faces up to situations which provoke its deterioration, and the Colombian teaching staff confronts aggression, and lack of acknowledgment, appraisal and incentives. This article presents to discussion the necessity for new meaning of the teaching profession from the integrated processes of permanent training and the teaching evaluation based on the tendencies of the personal and professional development which involve the qualitative transformation into a school improvement, and long-term practices which tend to get this object. These circumstances are also valid for the physical education profession.

Key words: $\quad$ New meaning of the teaching profession, physical education teachers, teaching evaluation, having to account, personal and professional development, permanent training.

Fecha de recepción: 28 de octubre de 2005.

Fecha de aceptación: 8 de noviembre de 2005.

Docente catedrática, investigadora. Facultad de educación fisica. Coinvestigadora grupo de investigación evaluando-nos. Universidad Pedagógica Nacional. 
El deterioro de la imagen y del estatus social que está sufriendo la profesión docente se extiende tanto en la difusa pero significativa conciencia social como en las determinaciones reales de las políticas educativas de las administraciones publicas o de las gestiones privadas o en el propio sentimiento de los docentes (Pérez Gómez, Ángel, 1989: 339).

\section{La situación actual}

Es necesario comprender la problemática para proponer la resignificación a partir de la evaluación pedagógica articulada a los procesos de formación. El análisis del tema debe incluir algunas reflexiones sobre el contexto económico, político, social y pedagógico que define y determina la practica profesional y permite comprender lo que acontece con el profesional de la educación en Colombia. Las perspectivas económicas y políticas de América Latina y nuestro país conducen a que la profesión docente pase por momentos difíciles y provoque incertidumbres en torno a su futuro. Se presenta debate respecto a la situación real del gremio; es de aclarar que el problema no se limita a las condiciones de contratación y a los pagos, sino al sentido y las responsabilidades que la sociedad le asigna a la escuela y a la profesión docente.

El modelo económico de corte neoliberal busca la eficiencia en la producción como indicador de éxito, se visualiza en metas concretas con indicadores de gestión precisos, definidos en términos financieros que giran en torno al traslado del esquema productivo con la tecnologización del trabajo educativo, la escuela se convierte en una empresa productiva, eficiente y autosuficiente, una mercancía que debe producir bienes cuantificables, una fábrica en serie; sus acciones se definen a partir de objetivos eminentemente economicistas, las competencias organizacionales prevalecen sobre las pedagógicas y se inserta un vocabulario técnico para dar cuenta de la gestión institucional, y terminar de consolidar el modelo administrativista y empresarial, en el cual se desconoce lo educativo, y lo pedagógico pasa a un segundo plano, porque el producto de la enseñanza es más importante que los procesos de aprendizaje; por ello el sistema educativo se enfrenta a su progresiva privatización.

En el contexto educativo actual se desarrolla una reforma curricular silenciosa y soterrada, con cambios superficiales en lo operativo y no en lo estructural, con la intención precisa de dar nuevo sentido a las prácticas en la escuela, posicionando la evaluación como eje del trabajo para el control que ejerce el Estado a las instituciones educativas, en especial en la gestión administrativa y financiera, porque se demanda calidad en la educación a partir de resultados cuantificables, a través de evaluaciones sobre los procesos y la gestión con indicadores financieros y administrativos.

Por lo anterior, puede afirmarse que el docente pasa a ser casi exclusivamente un técnico con funciones instrumentales, se desconoce el conocimiento del profesor en cuanto constructor de saber pedagógico. El problema, entonces, se prioriza lo anterior sobre el aprendizaje, la enseñanza y la persona humana. En general, se promueve y se posiciona la evaluación en el modelo de rendición de cuentas, como un proceso administrativo de control, inherente a la función docente.

\section{¿Qué es ser profesional en educación?}

Una gran confusión se presenta sobre lo que designan los conceptos profesión, profesional, profesionalización, profesionalidad y otros relacionados con el tema, lo cual se articula con los procesos de formación inicial y continuada y la evaluación docente. Igualmente el tema del estatus profesional y del estatuto docente adquiere un sentido profundo y se convierte en un problema ético y pedagógico en constante debate, atravesado por diversas fuerzas e intereses.

El quehacer docente es de naturaleza compleja, delicada y conflictiva; además, se supone que para mejorar la calidad de la educación y de los procesos de enseñanza es necesario transformar la escuela y modificar la función del docente para que colabore en el logro de los objetivos antes expuestos.

La docencia se consideró inicialmente como un apostolado, con una imagen religiosa y mítica, un proyecto de vida; no obstante, ha evolucionado y se ha desarrollado hasta la profesionalización y la estructuración de un escalafón docente, para ser considerada globalmente en aspectos concretos como: los roles y funciones del docente, las actitudes y aptitudes necesarias para desempeñar la profesión docente, la profesionalización de los docentes y la formación permanente en el saber pedagógico y disciplinar, además de lo ético y de la investigación al interior del aula.

El problema es qué concepto de profesionalidad se maneja. ¿El docente en Colombia es considerado profesional y las condiciones de trabajo afirman este sentido? Además, el Estado está favoreciendo y provocando el deterioro, el desprestigio y la desconsideración frente a la profesión docente. Popkewitz (1990) señala que los procesos de profesionalización se han usado en muchas ocasiones para introducir sistemas de racionalización en la enseñanza, con la consiguiente burocratización y pérdida de autonomía del profesor y la relegación de 
la participación social en la educación. $\mathrm{Al}$ respecto se expresa Imbernon: "El debate ha de cen-trarse no tanto en la profesión como en el desarrollo de esa cultura profesional... en el mismo sentido son permanentes las luchas que sólo se concentran en la búsqueda de condiciones laborales dignas". Teniendo en cuenta lo anterior, propone: "Se debe pasar de un profesional técnico a la cultura profesional que se va asumiendo de forma colectiva y democrática y que abre interesantes caminos a la profesión docente" (Imbernon, 2000: 180).

Algunos aspectos del problema se relacionan y son interdependientes; bien lo dice Labaree, citado por Ángel Pérez (2000): "Dos elementos claves configuran la identidad profesional de una actividad o quehacer practico: un determinado cuerpo de conocimientos formales y una reconocida autonomía de trabajo". El docente exige autonomía por ser él depositario del conocimiento especializado y es un experto a partir de un título otorgado por una institución de educación superior que lo identifica como profesional en las ciencias de la educación o en pedagogía, por ello tiene una responsabilidad con la sociedad respecto a su trabajo como profesional de la educación, que debe responder éticamente por la formación de los estudiantes a él encomendados. En nuestro caso, bien es cierto que el profesional de la educación física desarrolla su trabajo en múltiples campos de desempeño laboral, en prácticas relacionadas en forma directa o indirecta con la educación física, el deporte y la recreación. No obstante, el presente análisis se ubica en el contexto escolar por ser el espacio más tradicional y en el que el mayor número de egresados se encuentra vinculado.

La sociedad reconoce que el maestro posee un conocimiento experto que le posibilita desarrollar prácticas educativas y "lo identifica como perteneciente a un grupo profesional legitimado socialmente y con un sustento epistemológico para intervenir con cierta autonomía y responsabilidad en el campo específico de la educación" (Grundy, 1997: 126). En el mismo sentido, las normas, los procedimientos verticales y unilaterales, emanados del Ministerio de Educación Nacional y definidos por Planeación Nacional, hacen efectivas las directrices de los organismos prestamistas internacionales que definen las políticas, en algunos casos contradictorias; por ejemplo, el recorte de recursos versus la ampliación de la cobertura. En el mismo sentido el hecho se ratifica en: "El ejercicio de la carrera docente estará ligado a la evaluación permanente... verificará que en el desempeño de sus funciones los servidores docentes y directivos mantienen niveles de idoneidad, calidad y eficiencia que justifican la permanencia en el cargo, los ascensos en el escalafón y las reubicaciones en los niveles salariales dentro del mismo grado". (Decreto 1278 de 2002. Estatuto de Profesionalización Docente. Artículo 26).

En cuanto a la educación física, esta "se ha caracterizado por su variedad de acepciones, interpretaciones $y$, en tal sentido, por su indeterminación conceptual; asunto que no es extraño, si además se admite que su construcción ha sido fundamentalmente el producto de la reflexión y los aportes de otras disciplinas o ciencias" (Guía Curricular para la educación física. Modulo 02 Básica Primaria, 2003:13), lo cual influye en los imaginarios que de ella circulan en la escuela y en el nivel de reconocimiento social de sus profesionales.

A partir del hecho de que la educación física ha estado ubicada como asignatura curricular en la educación formal, donde más desarrollo ha alcanzado, "en su historia como asignatura escolar ha recibido influencias de concepciones y prácticas pedagógicas, militares, religiosas, médico-biológicas, psicológicas, deportivas, artísticas, recreativas y en consecuencia, su enseñanza se ha desarrollado con diferentes modelos pedagógicos que expresan teorías y formas de organización a través de las cuales se han conformado los hábitos, prácticas, conceptos y representaciones que ha tenido y tiene hoy la sociedad colombiana sobre el particular" (Lineamientos Curriculares de la Educación Física, 2000:20).

"La educación física desde sus inicios como profesión en 1936, ha centrado su atención y acción en el sector educativo, Por tal razón la formación de profesionales ha orientado hacia la preparación de licenciados con un perfil para su desempeño como docentes en los niveles de la educación básica y media vocacional" (Plan Nacional de Desarrollo de la Educación física, 2002: 46) por consiguiente los profesores del área, también afrontan la difícil situación de los demás educadores, antes descrita; adicionalmente el docente debe luchar por el fortalecimiento y resignificación de la educación física y la construcción del conocimiento en torno a ella.

\section{La evaluación}

En general, la evaluación se presenta como una estrategia pedagógica con el propósito de mejorar la calidad y lograr la excelencia educativa, intención válida en los diferentes discursos; sin embargo, lo que realmente busca es afianzar la rendición de cuentas y consolidar las políticas de control fiscal, la reacomodación financiera del Estado con los recortes presupuestales para la educación a través de la reducción de las plantas de 
personal. Recuérdese que la evaluación responde ante todo a lo económico, que es lo que define las políticas internacionales que afectan las estructuras pedagógicas y curriculares en los diferentes niveles educativos, que se adecuan a las exigencias de los organismos prestamistas multinacionales que al final de cuentas son las que concretan las orientaciones educativas para América Latina.

La evaluación en sus diferentes modalidades y prácticas en los últimos diez años ha adquirido un papel protagónico en el panorama educativo. Es una evaluación que por lo general ha sido autoritaria y definida en forma vertical. "Se ha entendido como medir, calificar, corregir, clasificar, examinar y aplicar test, que son actividades que desempeñan una labor instrumental... necesitamos aprender de y con la evaluación" (Álvarez Méndez. 2002. 12).

En cuanto a la evaluación docente, ésta es una de las modalidades que más debate ha generado, por las propuestas expedidas por el Estado para aplicarlas a los profesores que laboran en las instituciones oficiales. Puede afirmarse que la evaluación es postulada por los organismos internacionales y articulada a un sistema de contratación y al salario del docente que depende de su formación y desempeño que promueve el pago por merito.

En cambio, los profesores reconocen la evaluación como una posibilidad de mejorar la práctica docente; por ejemplo, los profesores del sector oficial rechazan que la evaluación sea presentada con fines distintos de los que realmente tiene. El Estado la muestra como estrategia para alcanzar la calidad y la excelencia educativas, pero en realidad tiene como fin el control técnico y la exclusión sin ningún proceso formativo real.

\section{Tendencias en la evaluación docente}

En la tendencia de rendición de cuentas prevalece un significado de control, inspección y vigilancia; por ello se supervisa y se examina cuanto sucede en la escuela. Está ligada a los resultados de los estudiantes, de hecho estos se premian o se castigan. Es aplicada como una evaluación externa, diseñada por un experto externo sin la participación de los evaluados. El eje está en el instrumento que se tiene que aplicar; un ejemplo lo constituyen las diversas evaluaciones masivas aplicadas a los escolares de la educación oficial (pruebas Saber). En síntesis, el interés está centrado en lo económico.
Por el contrario, la tendencia de evaluación de docentes como desarrollo personal y profesional "se concibe como un proceso de desarrollo, de crecimiento y perfeccionamiento permanente, en el que tiene prioridad el fortalecimiento de la profesión docente; a partir de la planificación y puesta en práctica de actividades de formación y evaluación, en forma negociada y democrática donde participe al colectivo docente".

El desarrollo profesional se caracteriza por la búsqueda de:

a. La comprensión de que el trabajo docente va más allá del aula, buscando un trabajo cooperativo que responda al concepto de comunidad académica.

b. Que el docente como profesional es creador y constructor de conocimientos, que lo llevan a investigar sobre sus prácticas.

c. Y que el docente reflexiona en la autoevaluación de su trabajo, en forma constante que le permite su mejora" (Evaluandonos Informe de investigación La Evaluación de Docentes desde el Desarrollo Profesional, 2003: 87).

En este proceso de desarrollo, de crecimiento, de cualificación y perfeccionamiento permanente, en el que tiene prioridad el fortalecimiento de la profesión y por ser el maestro integrante de una comunidad académica que busca el desarrollo individual, colectivo, profesional e institucional, se exige la propuesta de metas de formación del maestro en los planos individual e institucional.

Además, el desarrollo profesional requiere ciertas condiciones: comprender y reconocer cada contexto particular, establecer propósitos y planes de mejoramiento entre quienes están en el proceso, propiciar el tiempo necesario para la evaluación del colectivo docente, por cuanto este es un problema muy generalizado ante tantas tareas y el excesivo activismo implantado en los colegios desde la gestión. No queda tiempo ni nos hemos detenido a examinar y analizar el diseño, la implementación y el seguimiento de un sistema o sistemas de evaluación, de tal manera que se articula con el seguimiento de los planes y procesos de formación; porque esto incide en la permanencia en el cargo, la contratación, los estímulos, los reconocimientos y los ascensos. Un problema es el tiempo disponible del docente, mientras se piense que la función docente sólo es dictar clase. 


\section{Acciones para la resignificación de la profesión docente}

Es necesario presentar propuestas con un sentido pedagógico para los procesos integrados de formación permanente y de evaluación de los docentes, en particular los de educación física, que promuevan al profesor como persona y en general que la profesión docente no se quede como el desarrollo de una actividad técnica eminentemente instrumental.

Sobre la evaluación de docentes, deben definirse políticas que la promuevan y la articulen a la estructuración de un sistema de formación permanente, que sea un derecho y un deber del docente, con el diseño e implementación de procesos de formación continuada, de capacitación y actualización docente con ejes conceptuales y procedimientos, adaptados a sus características, necesidades e intereses y no como pro- cesos verticales, únicos y uniformes; pero, ante todo, la generación de proyectos de investigación para que el docente valore sus prácticas diarias desde una posición reflexiva frente a lo instituido a partir del análisis argumentado y crítico.

En general, puede decirse que los procesos de evaluación de docentes deben ser una posibilidad de crecimiento y una experiencia valiosa para las instituciones y los maestros, porque tradicionalmente no ha sido una opción de aprendizaje y crecimiento de los distintos actores de la comunidad educativa y de la institución. Además, es necesario que la voz del docente de educación física se escuche y se respete en espacios de participación que permitan atender las necesidades y aspiraciones sociales en materia de educación física y de desarrollo personal y profesional, pero con un compromiso orientado al análisis crítico y transformativo de sus propias prácticas y condiciones.

\section{Bibliografia}

ÁLVAREZ, Manuel y LÓPEZ, Juan. (1999). La evaluación del profesorado y equipos docentes. Madrid. Editorial Síntesis, S.A.

DIAZ BARRIG,A Ángel y ANCLAN, Catalina (2001). El docente en las reformas educativas: sujeto o ejecutor de proyectos ajenos. En Revista Iberoamericana de Educación. Organización de Estados Iberoamericanos.

DUKE, Daniel L. y STIGGINS, Richard J. (1997). Más allá de la competencia mínima: evaluación para el desarrollo profesional. En Manual para la evaluación del profesorado. Madrid.

FERNÁNDEZ ENGUITA, Mariano (2001). A la busca de un modelo profesional para la docencia: ¿̨liberal, burocrático o democrático? En Revista Iberoamericana de Educación. Madrid. Organización de Estados Iberoamericanos.

GUEVARA, Eliécer (2003). El oficio de maestro: nuestra razón de ser. En la revista Educación y Cultura. Número 62. Bogotá. CEID, Fecode.
GRUNDY, Shirley (1997). Mas allá de la profesionalidad. En Calidad de la enseñanza e investigación acción. CARR, Wilfred. Sevilla. Díada.

MINISTERIO DE EDUCACIÓN. ACPEF. (2002). Plan Nacional de Desarrollo de la Educación Física. Educación Física: Conocimiento y Construcción Social, 2002-2006.

MINISTERIO DE EDUCACIÓN (2000). Lineamientos Pedagógi$\cos$ y Curriculares de la educación física, Recreacióny Deportes. Decreto 1278 de 2002. Estatuto de Profesionalización Docente.

NIÑO ZAFRA, Libia Stella (2001). Las tendencias predominantes en la evaluación docente. En Revista Opciones Pedagógicas, Número 24. Serie Cuadernos de Educación. Bogotá. Universidad Distrital Francisco José de Caldas.

UNIVERSIDAD DE ANTIOQUIA, INDEPORTES ANTIOQUIA (2003). Guia Curricular para la educación física. Módulo 02 Básica Primaria. Medellín. 